\title{
The Anatomy of the Aging Face: A Review
}

\author{
Sebastian Cotofana, MD, PhD ${ }^{1,2}$ Alina A. M. Fratila, MD ${ }^{3}$ Thilo L. Schenck, MD \\ Wolfgang Redka-Swoboda, MD ${ }^{5}$ Isaac Zilinsky, MD ${ }^{6}$ Tatjana Pavicic, MD ${ }^{7}$
}

${ }^{1}$ Department of Anatomy, Ross University School of Medicine, Roseau,
Commonwealth of Dominica, West Indies
2 Institute of Anatomy, Paracelsus Medical University Salzburg \&
Nuremberg, Salzburg, Austria
${ }^{3}$ Jungbrunnen-Klinik GmbH, Bonn, Germany
${ }^{4}$ Department of Hand Surgery, Plastic Surgery and Aesthetic Surgery,
Ludwig-Maximilians University, Munich, Germany
${ }^{5}$ FaceSthetics, Munich, Germany
6 Department of Plastic and Reconstructive Surgery, Sheba Medical
Center, Tel Hashomer, Israel
7 Private Practice in Dermatology and Aesthetics, Munich, Germany

Address for correspondence Sebastian Cotofana, MD, PhD, Department of Anatomy, Ross University School of Medicine, P.O. Box 266, Roseau, Commonwealth of Dominica, West Indies (e-mail: sebastiancotofana@rossu.edu).

Facial Plast Surg 2016;32:253-260.

\begin{abstract}
Keywords

- facial bones

- fat compartments

- facial muscles

- facial ligaments

- aging

Rejuvenative procedures of the face are increasing in numbers, and a plethora of different therapeutic options are available today. Every procedure should aim for the patient's safety first and then for natural and long-lasting results. The face is one of the most complex regions in the human body and research continuously reveals new insights into the complex interplay of the different participating structures. Bone, ligaments, muscles, fat, and skin are the key players in the layered arrangement of the face.

Aging occurs in all involved facial structures but the onset and the speed of age-related changes differ between each specific structure, between each individual, and between different ethnic groups. Therefore, knowledge of age-related anatomy is crucial for a physician's work when trying to restore a youthful face.

This review focuses on the current understanding of the anatomy of the human face and tries to elucidate the morphological changes during aging of bone, ligaments, muscles, and fat, and their role in rejuvenative procedures.
\end{abstract}

The anatomy of the human face has received intensive attention during the last decade, as procedures of facial rejuvenation are being performed with increasing frequency and in numerous varieties. Several new anatomic structures have been identified, which help to understand one of the most complex areas of the human body (-Fig. 1). A plethora of invasive and noninvasive procedures have been introduced to reduce the signs of aging and to restore the youthful appearance of the face. As each of the different procedures is based on the underlying facial anatomy, the understanding of its three-dimensional composition and layered concept is crucial for safe, natural, and long-lasting applications. ${ }^{1}$

Issue Theme Nonsurgical Facial Rejuvenation; Guest Editors, Tanja C. Fischer, MD, and Gerd G. Gauglitz, MD, MMS
The trend in facial rejuvenative procedures points toward a more natural look compared with the previous empiric approaches, which resulted in a "pulled back" look. ${ }^{2}$ Today's rejuvenative options try to restore the natural balance between the different facial structures and facial layers and thus to give back to face what is lost during aging processes. ${ }^{1}$

Aging is the result of the interplay of changes occurring in the facial skeleton, facial ligaments, facial muscles, facial adipose tissue, and skin. These changes befall each mentioned structure at a different pace, start in each individual at a different age, and differ between ethnic background. ${ }^{3}$ Therefore, it is hard to estimate which structure is mainly causative
Copyright @ 2016 by Thieme Medical Publishers, Inc., 333 Seventh Avenue, New York, NY 10001, USA. Tel: +1(212) 584-4662.
DOI http://dx.doi.org/ 10.1055/s-0036-1582234. ISSN 0736-6825. 


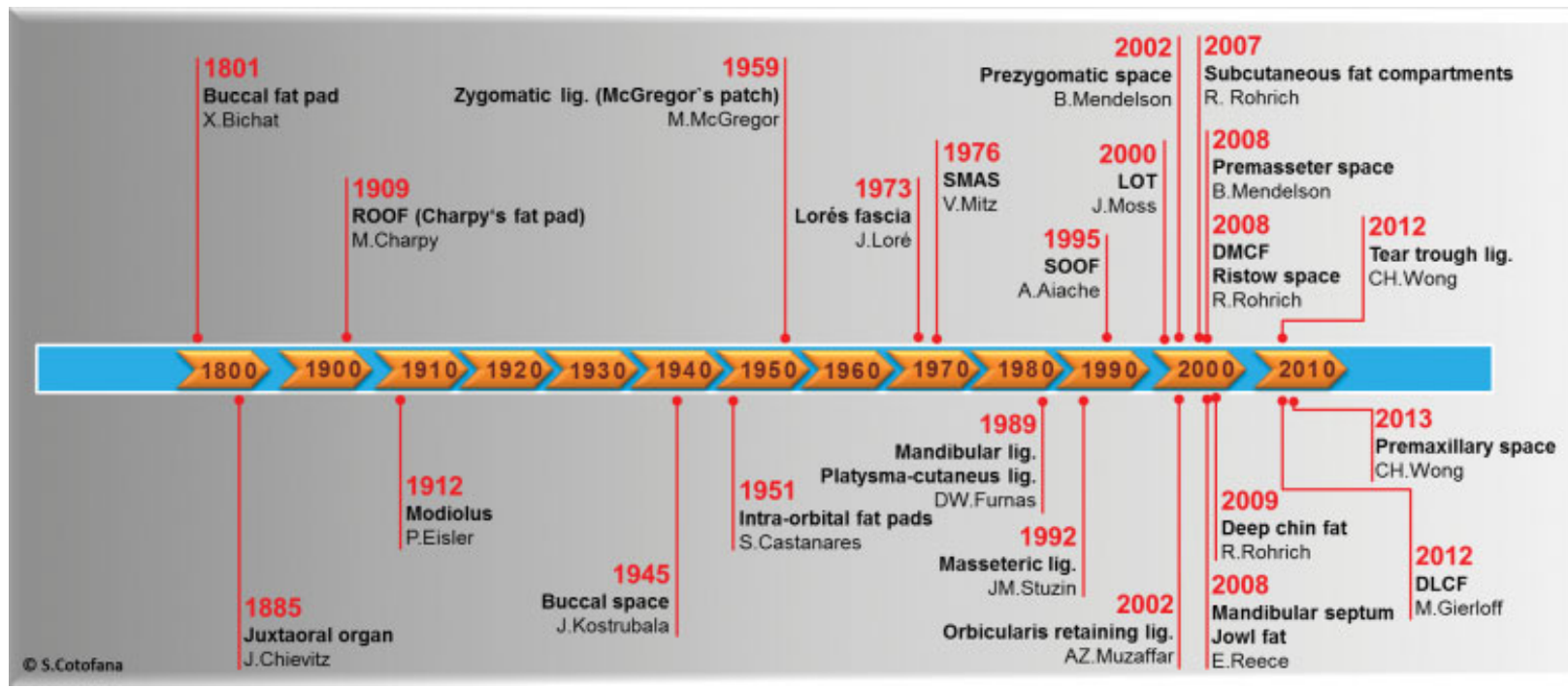

Fig. 1 Timeline from 1800 until now, showing the date of the first description of structures in the human face. DLCF, deep lateral cheek fat; DMCF, deep medial cheek fat; LOT, lateral orbital thickening; ROOF, retro-orbicularis oculi fat; SMAS, superficial musculoaponeurotic system; SOOF, suborbicularis oculi fat.

for the observed age-related feature. More research will be needed to elucidate these relationships in total.

\section{Facial Anatomy: The Layered Concept}

The face is organized in five different layers which are continuous with each other from the neck to the scalp. Within each layer, structures can be identified that are unique among the respective layer and are helpful for orientation and thus crucial for safe applications. Interestingly, the word scalp can serve as the acronym for these five different layers: layer 1 , $\mathrm{S}=$ skin; layer $2, \mathrm{C}=$ connective tissue, here subcutaneous fat layer; layer $3, \mathrm{~A}=$ aponeurosis also musculoaponeurotic layer; layer $4, \mathrm{~L}=$ loose connective tissue, also areolar connective tissue; and layer $5, \mathrm{P}=$ periosteum, also deep fascia. However, one has to have in mind that this arrangement is the general alignment of the structures in the face, but there are regions where this arrangement is changed toward less than five layers, for example, three layers in the infraorbital region, or toward more than five layers, for example, nine layers in the temporal region. ${ }^{4}$

\section{Skin (Layer 1)}

The skin has different characteristics in different areas of the face in terms of pigmentation, thickness, and subcutaneous adherence. In the infraorbital region, medial to the midpupillary line, the so-called tear trough area, the skin is thin, transparent, and firmly attached to the underlying orbicularis oculi muscle ( - Fig. 2). This arrangement can be best observed during movements of the skin when minute contractions of the orbital part of the orbicularis oculi muscle are performed during facial expressions. As the orbicularis oculi muscle is visible through the skin, a bluish coloring of the skin in this area is notable. It is noteworthy that on the medial nasal wall in the next proximity to the medial canthus the same bluish appearance can be detected, which corresponds to the extent of the underlying muscle. ${ }^{4}$ In the buccal and parotideomasseteric region, the skin lies on a variable thick layer of subcutaneous fat and has loose and variable connections to the underlying muscles of facial expression. In the perioral region, the skin is directly connected to the muscles of facial expression without a distinct subcutaneous fat layer in between and without a macroscopically identifiable aponeurotic structure present. ${ }^{5,6}$

\section{Connective Tissue (Layer 2)}

The subcutaneous fat layer varies in thickness and presence across the face. It is separated by fibrous septae into distinct compartments, which have been identified in several

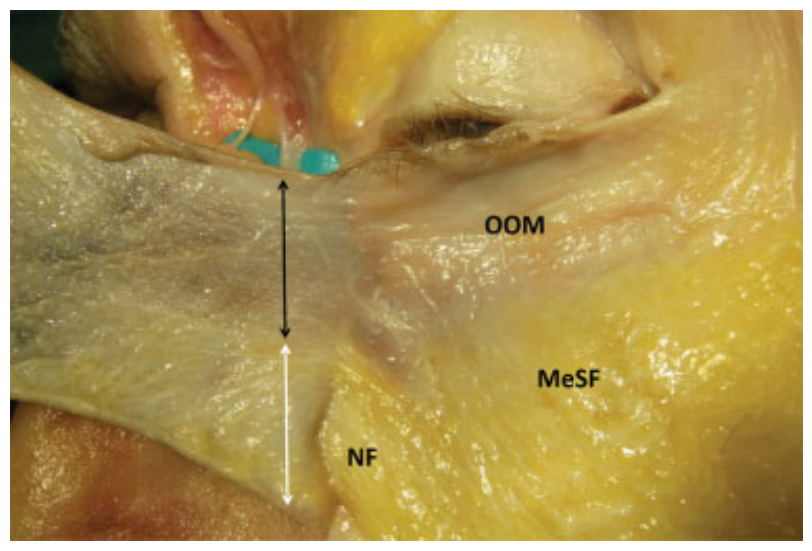

Fig. 2 The infraorbital region of the left eye in view from the left side. Sharp dissections between layer 1 (skin) and layer 2 (subcutaneous fat) was performed. MeSF, medial superficial fat, also called malar fat pad; $\mathrm{NF}$, nasolabial fat; OOM, orbicularis oculi muscle. White arrow indicates skin overlying the nasolabial fat compartment and black arrow skin overlying the infraorbital region. Please note the differences in skin characteristics which correspond to the boundaries of the compartments: skin in the infraorbital region is thin and transparent with absence of subcutaneous fat toward the underlying orbicularis oculi muscle. (Reprinted with permission of Merz Pharmaceuticals.) 
previous cadaveric ${ }^{4,7-9}$ and imaging studies. ${ }^{10}$ The fibrous septae serve as sheltered transit pathways for cutaneous nerves and vessels emerging from the depth and also provide attachment sites of the skin to the underlying muscles of facial expression, to other fasciae, or to the facial skeleton. As the muscles of facial expression have been shown to vary in position and course ${ }^{11-13}$ and also vary between individuals of different ethnic groups, ${ }^{14}$ it might be understandable why the subcutaneous fat compartments are variable in size and extent. ${ }^{4}$ The subcutaneous fat is separated by the musculoaponeurotic layer from the deep fat and is continuous with the general fat in the body. It also shows similar signs of volume increase during adipositas ( - Fig. 3 ), and it has been shown to have different morphological characteristics compared with the deep fat in the face. ${ }^{15}$ In the infraorbital region, the subcutanous fatty layer is generally absent and the very thin skin in this area appears transparent for the underlying orbicularis oculi muscle. In the perioral region, subcutanous fat cells are intermingled with skeletal muscle fibers and bundles of elastic collagens, which allow a precise movement of lips and the oral comissure. ${ }^{16}$

\section{Musculoaponeurotic (Layer 3)}

The musculoaponeurotic facial layer has received great attention during the last years, ${ }^{17}$ especially as the alteration of this layer, that is, shortening, duplication, or refixation, is the general basis for surgical facelift procedures. ${ }^{2,18,19}$ This layer can be identified in the neck as the superficial cervical fascia and contains the platysma muscle. In the face, this layer is continuous with the superficial musculoaponeurotic system (SMAS) and has unique biomechanical and viscoelastic properties. $^{16,20-22}$ The SMAS can be identified on the nose $\mathrm{e}^{23,24}$ and in the periorbital region-where the orbicularis oculi muscle is included in this layer. ${ }^{4}$ In the temporal region, this layer is continuous with the superficial temporal fascia ${ }^{25}$ and includes the anterior and the posterior branches of the superficial temporal artery. ${ }^{4}$ On the head, this layer is continuous with the galea aponeurotica and with the occipitofrontalis toward epicranius muscle. ${ }^{4}$ The origin of the zygomaticus major and minor muscle lies in the lateral midface (occipital to the masseteric ligaments) deep to this layer. In the medial midface (rostral to the masseteric ligaments), these muscles (and in some cases the risorius muscle as well ${ }^{13}$ ) pierce the SMAS and are henceforth included in this layer. Some authors describe this arrangement as the investing layer of the mimetic muscles, ${ }^{5}$ but this term has to be understood with caution, as muscles of facial expression lack an enveloping fascia, i.e., epimysium (exception: buccinator muscle).

\section{Loose Areolar (Layer 4)}

The loose areolar connective layer contains the deep fat and its compartments, and is separated in the face from the subcutaneous fat (layer 2) by the SMAS. The deep fat contains adipocytes, which are different in size compared with the superficial fat, ${ }^{15}$ and few authors attribute its function as the gliding plane for the muscles of facial expression. ${ }^{26,27}$ The deep fat is organized into distinct compartments, and the boundaries of these compartments serve as transition pathways for facial nerve branches ${ }^{28-30}$ and for the branches of the facial artery and vein. The deep fat compartments have been recently confirmed both in cadaveric ${ }^{31,32}$ and in imaging studies $^{33}$ but their existence has long been known and postulated; for example, the first description of the retroorbicularis oculi fat (ROOF) pad was first described in $1909^{34}$ and the suborbicularis oculi fat (SOOF) pad in $1995 .{ }^{35}$ In the temporal region, this layer is almost absent in the upper temporal compartment but varies during aging in the lower

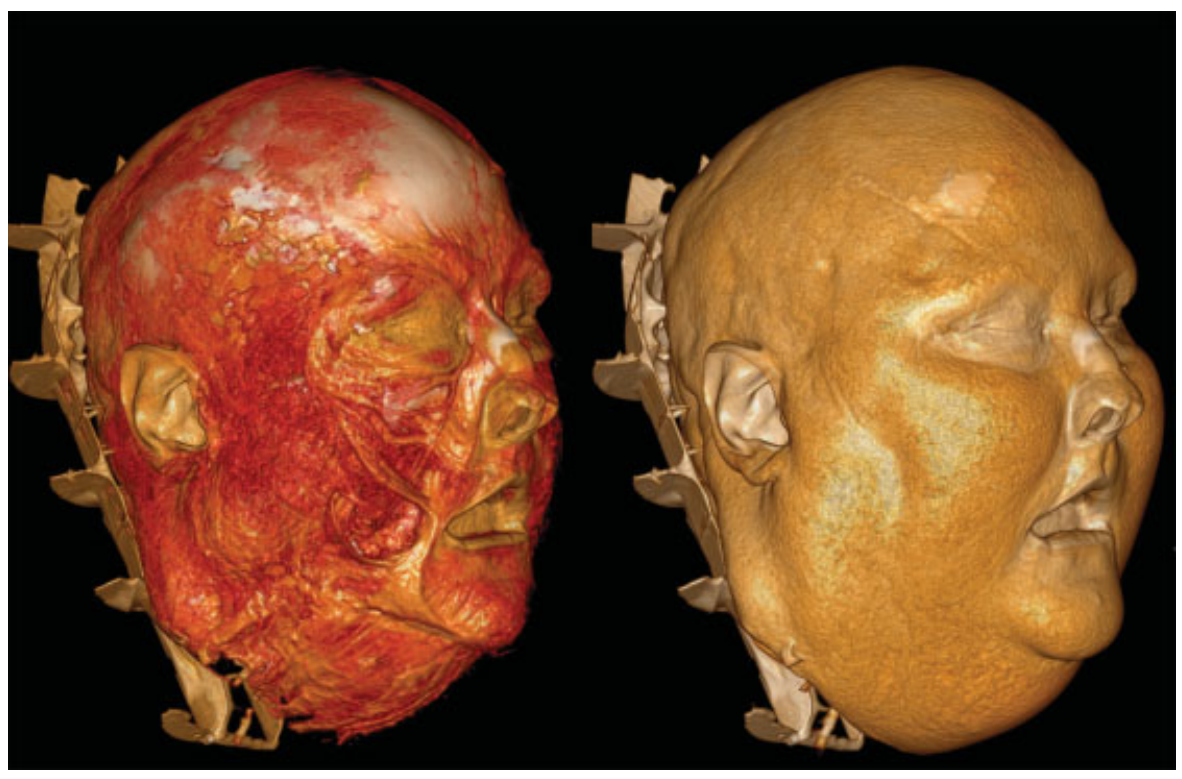

Fig. 3 Postmortem computed tomography scan of an adipose fresh-frozen cadaver. Image on the left side shows the structures deep to layer 3 (SMAS), that is, muscles and deep fat. Image on the right includes additionally the structures included in layer 2 and 1 (subcutaneous fat and skin). Please note that the prominences in the submental and submandibular region are caused by traction of gravity and not by bulging of structures deep to the platysma. (Reprinted with permission of Merz Pharmaceuticals.) 
temporal compartment, where it also shelters the temporal branches of the facial nerve. ${ }^{25}$ However, there are still fat compartments that need to be confirmed in this layer, for example, the deep nasolabial fat compartment, which will complete the understanding of facial anatomy and will have an impact on future rejuvenative applications.

\section{Periosteum (Layer 5)}

The name of this layer is deducted from the scalp where layer 5 is covering the bone and only the bare bone can be identified deep to it. In other parts of the face, layer 5 is identifiable as a distinct structure, which is not the periosteum. In the temple, this layer is called deep temporal fascia and includes the superficial temporal fat pad. ${ }^{36}$ In the lateral midface, this layer is called parotideomasseteric fascia ${ }^{4}$ and in the neck it is continuous with the investing layer of the deep cervical fascia. However, the scientific evidence of its continuousness is the subject of current research and its result will contribute to a new understanding of facial anatomy. Deep to this layer, the temporalis muscle and the temporal extension of the buccal fat pad can be identified in the temporal region. ${ }^{37-40}$ In the lateral midface (occipital to the masseteric ligaments), the parotid gland, the occipital one-third of the parotid duct, the accessory parotid gland, the origin of the zygomatic muscles, and the branches of the facial nerve emerging from the parotid plexus can be identified. In the medial midface (rostral to the masseteric ligaments), this layer envelopes the parotid duct and forms the fascia of the facial vein before it attaches to the buccopharyngeal fascia and the buccinator muscle. ${ }^{4}$ In the periorbital region, however, the superficial lamina (not the deep lamina) of the deep temporal fascia continues toward the orbit and separates the SOOF from the prezygomatic space. ${ }^{41}$ Medial to the facial vein, this layer is continuous with the periosteum of the facial skeleton and is connected to the epineurium of the infraorbital nerve.

\section{Age-Related Changes}

\section{Facial Bones}

The bony skeleton of the face serves as the scaffolding for the overlying soft tissue masses and can be regarded as the fundament of facial rejuvenative procedures. It is currently accepted that the facial skeleton undergoes lifelong and continuous changes and that these changes affect the appearance of the face and its expressions., ${ }^{3,42,43}$ An early study summarized the changes occurring in the facial skeleton and set the basis for our current understanding of facial changes during aging as follows ${ }^{44}$ : lateral translation of the orbits; protrusion of the glabella; expansion of the supraorbital ridges; increase in the depth and lateral expansion of the cheeks; increase in length, width, and vertical dimensions of the nose; and increase in vertical height in the occlusal region associated with increased chin prominence. ${ }^{43}$ Based on these changes, the Lambros theory of clockwise rotation of the viscerocranium (when viewed from the right) was postulated. ${ }^{45,46} \mathrm{~A}$ recent study measured in a Caucasian population different facial angles and reported that the glabellar, orbital, maxillary, and pyriform angles decrease with age and that the maxillary, pyriform, and infraorbital rim also regress with age. ${ }^{42}$ Another study carried out in an Asian population found similar results; however, the orbital and maxillary angles showed less changes and the pyriform angle showed more prominent changes compared to studies conducted in Caucasian populations. ${ }^{3}$ The resulting changes of the facial skeleton not only are causative for the overall facial shape but also affect the position, that is, the origin of ligaments and the overlying fat compartments. A decrease of the maxillary angle might be causative for the expansion of the inferior orbital rim and thus of an anterior positioning of the orbital septum. ${ }^{43}$ Thus, a pseudoprolapse of the intraorbital = retroseptal fat pads might be facilitated as the retaining capability is reduced and the clinical sign of palpebral bags might be aggravated. Also, the orbicularis retaining ligament might lose it horizontal position $^{47-51}$ toward a more inferior inclined alignment, causing loss of stability of the adjacent orbicularis oculi muscle, which forms the anterior wall of the underlying fat compartments above the orbital aperture, that is, ROOF, and below the aperture, that is, SOOF (-Fig. 4, blue and red circles).

\section{Facial Ligaments}

Several ligaments in the face have been identified, ${ }^{52,53}$ and of those, the zygomatic ligament has been shown to be biomechanically the stiffest, followed by the orbital retaining and the mandibular ligament. ${ }^{54}$ It is of importance to note that the zygomatic ligament extends from the zygomatic arch toward the orbital rim and connects with the orbicularis retaining ligament medial to the midpupillary line. From this merging point, the orbicularis retaining ligament changes its name and is called from here on tear trough ligament. Due to its extensive course, the zygomatic ligament (sometimes in total also called zygomatico-cutaneous ligaments ${ }^{55}$ ) forms the hammock of the SOOF. ${ }^{4}$ The most posterior part of this ligament is called McGregor patch ${ }^{56}$ and is regarded by some authors as the one zygomatic ligament. ${ }^{1}$ The ligaments of the face are composed of collagens, proteoglycans, glycosaminoglycans (GAG), and water. The correct interplay of the proteins along with an intrafascicular lubrication provide a proper mechanical competence. It has been postulated that ligaments may not undergo age-related changes. ${ }^{1,54}$ A study conducted in medial collateral ligaments of the knee in rabbits $^{57}$ reported that collagen, GAG content, and water content did not demonstrate age-related changes, whereas Lubricin/PRG4 gene expression was affected by aging. The authors speculated that its role in ligament function may be related to interfascicular lubrication, which in turn may lead to altered mechanical function with aging. ${ }^{57}$ Due to agerelated changes of bone, the points of origin and thus their firm adhesions to skin and other adjacent structures are getting affected as the position of the ligament and thus its course are getting altered. Also during aging, the stability of a ligament that serves as a hammock for the fat within each compartment (superficial or deep) has been argued to show fatigue and to bend along its course and thus to promote the appearance of sagging of the respective fat compartment, which can be observed as the jowl deformity in aging individuals (-Fig. 4, black circle). ${ }^{58}$ 


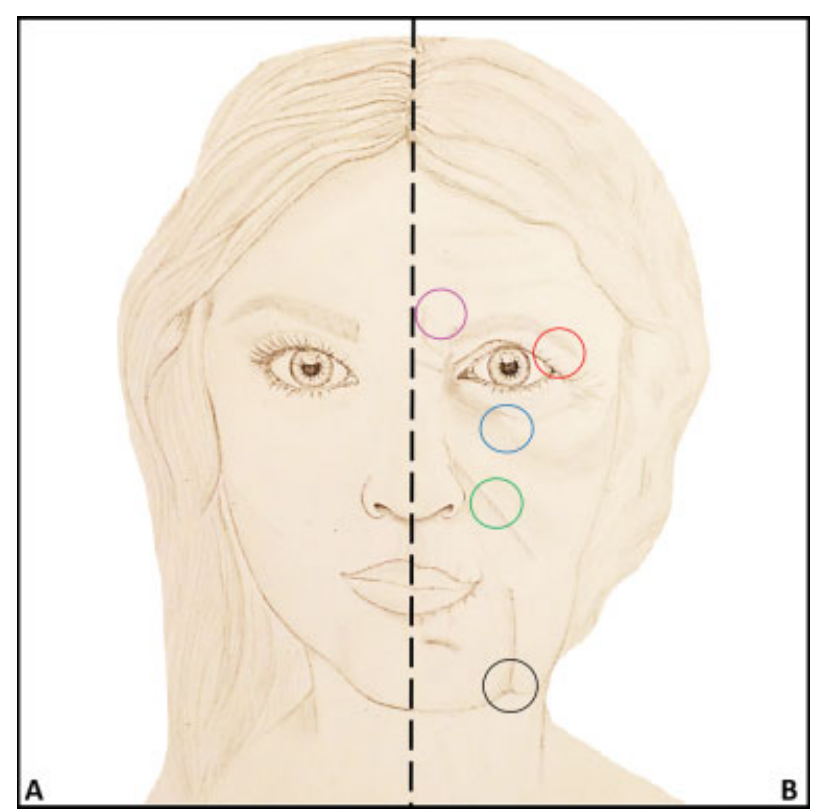

Fig. 4 Drawn image of a youthful (A) and an aged face (B). Different colored circles show areas where the anatomy of facial aging is explained. Pink circle: horizontal and vertical wrinkles in the glabellar region due to effects of the procerus, corrugator supercilii, depressor supercilii, and orbicularis oculi muscles. Red circle: sagging of the retroorbicularis oculi fat (ROOF) compartment due to laxity of the orbicularis oculi muscle, orbicularis retaining ligament, and frontalis muscle, and due to changes of the underlying bone. Blue circle: area where the zygomatic and the orbicularis retaining ligaments merge to form the tear trough ligament. This area is the medial boundary of the suborbicularis oculi fat (SOOF) compartment and has a triangular impression. The inferior boundary of the SOOF is the zygomatic ligament. Laxity of the latter, the orbicularis retaining ligament, changes of the bony orbital rim, and the respective fat compartments in that area are additionally causative for the appearance of malar mounds. Green circle: the nasolabial sulcus is formed by the overlying superficial nasolabial fat compartment and the traction of the underlying muscles of facial expression. This impression is increased during aging as changes occur in the bone of the orbital rim, the orbicularis retaining ligament, the zygomatic ligament, the orbicularis oculi muscle, and the superficial musculoaponeurotic system (SMAS). Black circle: The mandibular ligament attaches the skin and all adjacent structures to the bone. The structures posterior to it including the superficial and deep fat compartments are more loosely attached and are thus capable to migrate inferiorly and to form the jowl deformity.

\section{Facial Muscles}

The physiologic age-dependent process of loosing mass and proper function of muscles is called sarcopenia. ${ }^{59,60}$ The facial muscles, in specific, lengthen with age, increase in muscle tone, and have a shorter amplitude of movement, and the muscle tone at rest is closer to maximum contracture tone. ${ }^{61}$ The clinical effect of these changes might be a general tightening of the muscles of the face, with a limited amplitude of facial expression, permanent contractures which result in a potential shifting of fat and thus an accentuation of skin creases, and permanent skin wrinkling with a transformation of dynamic facial lines to static facial lines (-Fig. 4, pink circle). ${ }^{62}$ Recent studies trying to restore muscle function with facial muscle exercises, however, revealed limited efficacy, ${ }^{63}$ whereas the use of neuromuscular electrical stimula- tion reported promising results. ${ }^{60}$ However, the observed clinical changes could be due to changes of altered muscle physiology itself or secondary to age-related changes of facial bones and ligaments. As the latter is considered as the more appropriate approach, procedures for facial rejuvenation should integrate all facial tissue into consideration for natural results.

\section{Facial Fat}

The adipose tissue of the face can be subdivided into superficial fat (layer 2) and deep fat (layer 4), which are separated by the SMAS (layer 3). ${ }^{4}$ Both the superficial and the deep fat are organized in specific fat compartments, which are bordered by septae, fasciae, ligaments, or muscles. ${ }^{4}$ The fat within each compartment provides volume and stability and contributes thus to the general appearance of the face. ${ }^{10}$ It has been shown that the fat in the deep compartments is composed of adipocytes of smaller size ${ }^{15}$ and of different morphological appareance ${ }^{64}$ when compared with superficial fat characteristics. Some authors attribute a gliding function for facial muscles to the deep fat, as it surrounds some of the facial muscles next to deep fat compartments (e.g., zygomatic muscles). ${ }^{26}$ However, this function seems questionable as it is known that most of the facial muscles change planes from layer 5 to layer 2 and are thus surrounded by superficial fat too. Furthermore, facial muscles have the specific function to transfer each contractile movement to the overlying skin or the adjacent SMAS, which might be hampered when the surrounding fat has the function of a protective envelope. ${ }^{4}$ Some authors reported previously that some superficial fat compartments, for example, the superficial nasolabial fat compartment, undergo hypertrophy during aging, as the measured volume in the respective compartments increased between different groups of age. ${ }^{10,27,61}$ Looking clinically at the nasolabial compartment, a noticeable increase of the prominence of this superficial fat compartment is detectable during aging. The nasolabial fold is the transition line between the subcutaneous arrangement of type 1 (presence of large amounts of fat cells, i.e., compartments) toward type 2 (small amount or single fat cells interwoven by a complex meshwork of collagen fibers) ${ }^{16}$ and can be regarded as the line (along with the labiomental sulcus) where the distinct and compartmentalized subcutaneous fat compartments end. ${ }^{4}$ As the subcutaneous fat compartment superior to this sulcus loses its stability due to changes of the aging facial bone, ligamentous fatigue, ${ }^{58}$ laxity of the overlying skin, altered muscle physiology, and gravity, the fat has the tendency to shift inferiorly. The muscles of facial expression, however, have strong connections to the nasolabial sulcus ${ }^{5}$ and border the nasolabial fat compartment inferiorly along with the terminating part of the SMAS (-Fig. 5). The fat is unable to migrate deep to the fold inferiorly but is forced superiorly and thus a bulging of fat overlying the sulcus is clinically visible. As some of the previous studies might not have precisely delineated the deep boundary of this compartment or might not have accounted for changes of the facial skeleton or might have methodological differences in their study designs, ${ }^{27}$ the 


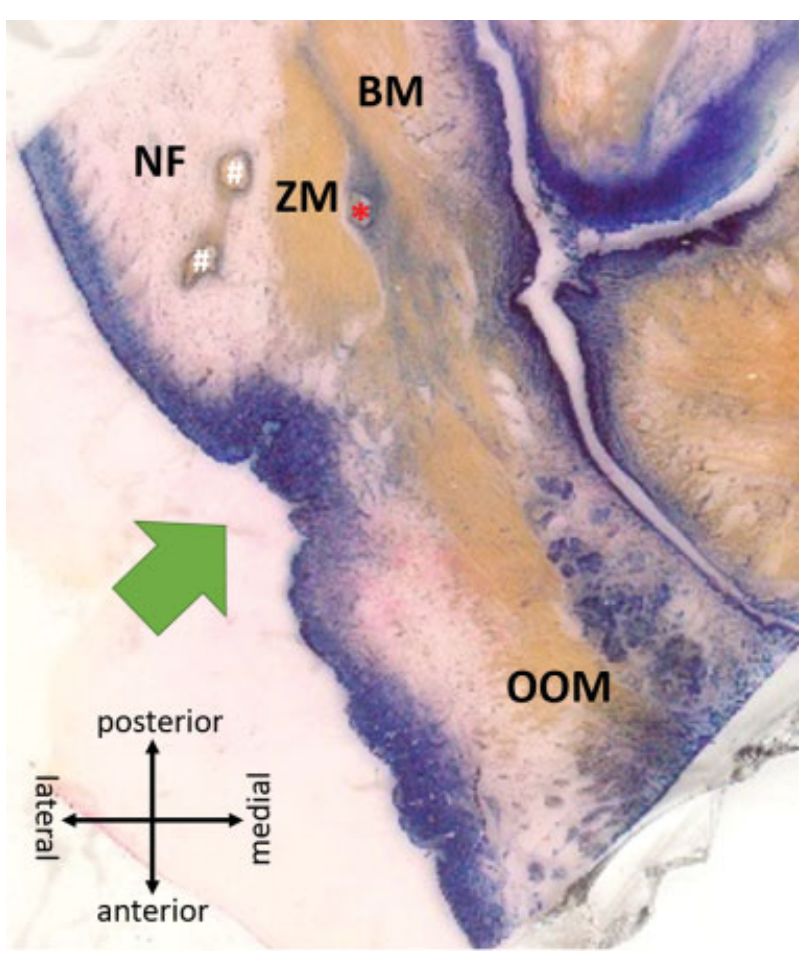

Fig. 5 Histologic cross-sectional analysis of the right nasolabial sulcus (green arrow) in view from superior. Muscles are shown in orange and collagen fibers in blue. BM, buccinator muscle; NF, nasolabial fat; OOM, orbicularis oris muscle; ZM, zygomaticus major muscle. The red asterisk indicates facial artery and white hash-marks indicate branches of transverse facial artery. Please note that the zygomaticus major muscle and the buccinator muscle connect with each other and have strong adhesions toward the skin forming the nasolabial sulcus. After the nasolabial sulcus, the zygomaticus major and the buccinator muscle merge with the orbicularis oris muscle.

reported discrepancy in the presented results might be understandable.

\section{Conclusion}

The face is arranged in five distinct layers and each layer is composed of specific structures which contribute differently to the appearance of an aging face. Considerations of the interplay between bone, ligaments, muscles, and fat have to be taken into account to achieve safe, natural, and long-lasting rejuvenative effects. As a plethora of multiple approaches are available for strategically restoring the youthful appearance, one has to have in mind that in some dedicated cases minimal invasive procedures might not lead to a satisfying result. Therefore, surgical interventions such as deep fat compartment mobilization, muscle origin relocation, or bone expansion with implants by using a subperiosteal approach might be indicated, especially in the central oval of the face. Independent of the strategy used, one has to be aware of the complex underlying anatomy and account for the contribution of each different structure to the aging face to guide the most appropriate rejuvenative therapy for the patient.

\section{Author Disclosures}

S. C. provides consulting service for anatomical education to Merz Pharmaceuticals GmbH. W. R.-S. provides consulting service to Teoxane Laboratoires Geneva. T. P. is a consultant and speaker for Merz Pharmaceuticals $\mathrm{GmbH}$, Galderma S.A., Dermaceutic Laboratoires, and Cynosure Inc.

\section{Acknowledgments}

We would like to thank Hanno Steinke from the Institute of Anatomy, University of Leipzig, Germany and Sarah Marie Freibuchner for their dedicated contribution to this work.

\section{References}

1 Wong $\mathrm{CH}$, Mendelson B. Newer understanding of specific anatomic targets in the aging face as applied to injectables: aging changes in the craniofacial skeleton and facial ligaments. Plast Reconstr Surg 2015;136(5, Suppl):44S-48S

2 Zimbler MS. Tord skoog: face-lift innovator. Arch Facial Plast Surg 2001;3(1):63

3 Kim SJ, Kim SJ, Park JS, Byun SW, Bae JH. Analysis of age-related changes in asian facial skeletons using $3 \mathrm{D}$ vector mathematics on picture archiving and communication system computed tomography. Yonsei Med J 2015;56(5):1395-1400

4 Cotofana S, Schenck TL, Trevidic P, et al. Midface: clinical anatomy and regional approaches with injectable fillers. Plast Reconstr Surg 2015;136(5, Suppl):219S-234S

5 Beer GM, Manestar M, Mihic-Probst D. The causes of the nasolabial crease: a histomorphological study. Clin Anat 2013;26(2):196-203

6 Zufferey J. Anatomic variations of the nasolabial fold. Plast Reconstr Surg 1992;89(2):225-231, discussion 232-233

7 Pilsl U, Anderhuber F. The chin and adjacent fat compartments. Dermatol Surg 2010;36(2):214-218

8 Pilsl U, Anderhuber F. The septum subcutaneum parotideomassetericum. Dermatol Surg 2010;36(12):2005-2008

9 Rohrich RJ, Pessa JE. The fat compartments of the face: anatomy and clinical implications for cosmetic surgery. Plast Reconstr Surg 2007;119(7):2219-2227, discussion 2228-2231

10 Gierloff M, Stöhring C, Buder T, Wiltfang J. The subcutaneous fat compartments in relation to aesthetically important facial folds and rhytides. J Plast Reconstr Aesthet Surg 2012;65(10):1292-1297

11 Pessa JE, Zadoo VP, Adrian EK Jr, Yuan CH, Aydelotte J, Garza JR. Variability of the midfacial muscles: analysis of 50 hemifacial cadaver dissections. Plast Reconstr Surg 1998;102(6): 1888-1893

12 Shim KS, Hu KS, Kwak HH, et al. An anatomical study of the insertion of the zygomaticus major muscle in humans focused on the muscle arrangement at the corner of the mouth. Plast Reconstr Surg 2008;121(2):466-473, discussion 474

$13 \mathrm{Bae} \mathrm{JH}$, Lee JH, Youn $\mathrm{KH}$, et al. Surgical consideration of the anatomic origin of the risorius in relation to facial planes. Aesthet Surg J 2014;34(7):NP43-NP49

14 Farahvash MR, Abianeh SH, Farahvash B, Farahvash Y, Yagoobi A, Nazparvar B. Anatomic variations of midfacial muscles and nasolabial crease: a survey on 52 hemifacial dissections in fresh Persian cadavers. Aesthet Surg J 2010;30(1):17-21

15 Wan D, Amirlak B, Giessler P, et al. The differing adipocyte morphologies of deep versus superficial midfacial fat compartments: a cadaveric study. Plast Reconstr Surg 2014;133(5):615e-622e

16 Ghassemi A, Prescher A, Riediger D, Axer H. Anatomy of the SMAS revisited. Aesthetic Plast Surg 2003;27(4):258-264 
17 Mitz V, Peyronie M. The superficial musculo-aponeurotic system (SMAS) in the parotid and cheek area. Plast Reconstr Surg 1976; 58(1):80-88

18 Gladstone GJ, Myint S, Black EH, Brazzo BG, Nesi FA. Fundamentals of facelift surgery. Ophthalmol Clin North Am 2005;18(2): 311-317, vii

19 Marten TJ. High SMAS facelift: combined single flap lifting of the jawline, cheek, and midface. Clin Plast Surg 2008;35(4):569-603, vi-vii

20 Har-Shai Y, Sela E, Rubinstien I, Lindenbaum ES, Mitz V, Hirshowitz B. Computerized morphometric quantitation of elastin and collagen in SMAS and facial skin and the possible role of fat cells in SMAS viscoelastic properties. Plast Reconstr Surg 1998;102(7): 2466-2470

21 Har-Shai Y, Bodner SR, Egozy-Golan D, et al. Viscoelastic properties of the superficial musculoaponeurotic system (SMAS): a microscopic and mechanical study. Aesthetic Plast Surg 1997;21(4): 219-224

22 Saulis AS, Lautenschlager EP, Mustoe TA. Biomechanical and viscoelastic properties of skin, SMAS, and composite flaps as they pertain to rhytidectomy. Plast Reconstr Surg 2002;110(2): 590-598, discussion 599-600

23 Ozturk CN, Larson JD, Ozturk C, Zins JE. The SMAS and fat compartments of the nose: an anatomical study. Aesthetic Plast Surg 2013; 37(1):11-15

24 Saban Y, Andretto Amodeo C, Hammou JC, Polselli R. An anatomical study of the nasal superficial musculoaponeurotic system: surgical applications in rhinoplasty. Arch Facial Plast Surg 2008; 10(2):109-115

25 O'Brien JX, Ashton MW, Rozen WM, Ross R, Mendelson BC. New perspectives on the surgical anatomy and nomenclature of the temporal region: literature review and dissection study. Plast Reconstr Surg 2013;131(3):510-522

26 Dumont T, Simon E, Stricker M, Kahn JL, Chassagne JF. Facial fat: descriptive and functional anatomy, from a review of literature and dissections of 10 split-faces. Ann Chir Plast Esthet 2007;52(1): 51-61

27 Gerth DJ. Structural and volumetric changes in the aging face. Facial Plast Surg 2015;31(1):3-9

28 Mendelson BC, Freeman ME, Wu W, Huggins RJ. Surgical anatomy of the lower face: the premasseter space, the jowl, and the labiomandibular fold. Aesthetic Plast Surg 2008;32(2):185-195

29 Mendelson BC, Wong CH. Surgical anatomy of the middle premasseter space and its application in sub-SMAS face lift surgery. Plast Reconstr Surg 2013;132(1):57-64

30 Wong $\mathrm{CH}$, Mendelson B. Facial soft-tissue spaces and retaining ligaments of the midcheek: defining the premaxillary space. Plast Reconstr Surg 2013;132(1):49-56

31 Rohrich RJ, Arbique GM, Wong C, Brown S, Pessa JE. The anatomy of suborbicularis fat: implications for periorbital rejuvenation. Plast Reconstr Surg 2009;124(3):946-951

32 Rohrich RJ, Pessa JE, Ristow B. The youthful cheek and the deep medial fat compartment. Plast Reconstr Surg 2008;121(6):2107-2112

33 Gierloff M, Stöhring C, Buder T, Gassling V, Açil Y, Wiltfang J. Aging changes of the midfacial fat compartments: a computed tomographic study. Plast Reconstr Surg 2012;129(1):263-273

34 Aghai F, Caix P. The retro-orbicularis oculus fat (ROOF) or Charpy's fat pad. Descriptive and functional anatomy. Surgical concepts applied to the design of a frontotemporal lift procedure. Ann Chir Plast Esthet 2004;49(4):355-359

35 Aiache AE, Ramirez OH. The suborbicularis oculi fat pads: an anatomic and clinical study. Plast Reconstr Surg 1995;95(1):37-42

36 Sykes JM, Cotofana S, Trevidic P, et al. Upper face: clinical anatomy and regional approaches with injectable fillers. Plast Reconstr Surg 2015;136(5, Suppl):204S-218S

37 Loukas M, Kapos T, Louis RG Jr, Wartman C, Jones A, Hallner B. Gross anatomical, CT and MRI analyses of the buccal fat pad with special emphasis on volumetric variations. Surg Radiol Anat 2006; 28(3):254-260

38 Rácz L, Maros TN, Seres-Sturm L. Structural characteristics and functional significance of the buccal fat pad (corpus adiposum buccae). Morphol Embryol (Bucur) 1989;35(2):73-77

39 Stuzin JM, Wagstrom L, Kawamoto HK, Baker TJ, Wolfe SA. The anatomy and clinical applications of the buccal fat pad. Plast Reconstr Surg 1990;85(1):29-37

40 Yousuf S, Tubbs RS, Wartmann CT, Kapos T, Cohen-Gadol AA, Loukas M. A review of the gross anatomy, functions, pathology, and clinical uses of the buccal fat pad. Surg Radiol Anat 2010; 32(5):427-436

41 Mendelson BC, Muzaffar AR, Adams WP Jr. Surgical anatomy of the midcheek and malar mounds. Plast Reconstr Surg 2002;110(3): 885-896, discussion 897-911

42 Richard MJ, Morris C, Deen BF, Gray L, Woodward JA. Analysis of the anatomic changes of the aging facial skeleton using computer-assisted tomography. Ophthal Plast Reconstr Surg 2009;25(5):382-386

43 Mendelson B, Wong $\mathrm{CH}$. Changes in the facial skeleton with aging: implications and clinical applications in facial rejuvenation. Aesthetic Plast Surg 2012;36(4):753-760

44 Enlow DH. A morphogenetic analysis of facial growth. Am J Orthod 1966;52(4):283-299

45 Pessa JE. An algorithm of facial aging: verification of Lambros's theory by three-dimensional stereolithography, with reference to the pathogenesis of midfacial aging, scleral show, and the lateral suborbital trough deformity. Plast Reconstr Surg 2000;106(2): 479-488, discussion 489-490

46 Pessa JE, Chen Y. Curve analysis of the aging orbital aperture. Plast Reconstr Surg 2002;109(2):751-755, discussion 756-760

47 Flowers RS. Tear trough implants for correction of tear trough deformity. Clin Plast Surg 1993;20(2):403-415

48 Haddock NT, Saadeh PB, Boutros S, Thorne $\mathrm{CH}$. The tear trough and lid/cheek junction: anatomy and implications for surgical correction. Plast Reconstr Surg 2009;123(4):1332-1340, discussion 1341-1342

49 Hirmand H. Anatomy and nonsurgical correction of the tear trough deformity. Plast Reconstr Surg 2010;125(2):699-708

50 Wong $\mathrm{CH}$, Hsieh MK, Mendelson B. The tear trough ligament: anatomical basis for the tear trough deformity. Plast Reconstr Surg 2012;129(6):1392-1402

51 Yang C, Zhang P, Xing X. Tear trough and palpebromalar groove in young versus elderly adults: a sectional anatomy study. Plast Reconstr Surg 2013;132(4):796-808

52 Furnas DW. The retaining ligaments of the cheek. Plast Reconstr Surg 1989;83(1):11-16

53 Stuzin JM, Baker TJ, Gordon HL. The relationship of the superficial and deep facial fascias: relevance to rhytidectomy and aging. Plast Reconstr Surg 1992;89(3):441-449, discussion 450-451

54 Brandt MG, Hassa A, Roth K, Wehrli B, Moore CC. Biomechanical properties of the facial retaining ligaments. Arch Facial Plast Surg 2012;14(4):289-294

55 Fratila AAM, Zubcov-Iwantscheff A, Coleman WP. Illustrated Guide to Eyelid and Periorbital Surgery: Applied Anatomy, Examination, Blepharoplasty. Hanover Park, IL: Quintessence Publishing Company; 2014

56 McGregor M. Face lift techniques. Paper presented at: the Annual Meeting of the California Society of Plastic Surgeons; 1959; Yosemite, CA

57 Thornton GM, Lemmex DB, Ono Y, et al. Aging affects mechanical properties and lubricin/PRG4 gene expression in normal ligaments. J Biomech 2015;48(12):3306-3311

58 Kretlow JD, Hollier LH Jr, Hatef DA. The facial aging debate of deflation versus attenuation: attenuation strikes back. Plast Reconstr Surg 2012;130(1):180e-181e, author reply 182e

59 Campbell MJ, McComas AJ, Petito F. Physiological changes in ageing muscles. J Neurol Neurosurg Psychiatry 1973;36(2):174-182 
60 Kavanagh S, Newell J, Hennessy M, Sadick N. Use of a neuromuscular electrical stimulation device for facial muscle toning: a randomized, controlled trial. J Cosmet Dermatol 2012;11(4):261-266

61 Le Louarn C, Buthiau D, Buis J. Structural aging: the facial recurve concept. Aesthetic Plast Surg 2007;31(3):213-218

62 George RM, Singer R. The lines and grooves of the face: a suggested nomenclature. Plast Reconstr Surg 1993;92(3):540-542
63 De Vos MC, Van den Brande H, Boone B, Van Borsel J. Facial exercises for facial rejuvenation: a control group study. Folia Phoniatr Logop 2013;65(3):117-122

64 Andretto Amodeo C, Casasco A, Icaro Cornaglia A, Kang R, Keller GS. The suborbicularis oculi fat (SOOF) and the fascial planes: has everything already been explained? JAMA Facial Plast Surg 2014; 16(1):36-41 